\title{
Os Conceitos Jurídicos e a Doutrina Real do Direito
}

\author{
Eros Roberto Grau \\ Professor Adjunto da Faculdade de Direito \\ da Universidade de São Paulo
}

\section{Introdução}

01. - Tenho desenvolvido, de dois anos para cá, pesquisa atinente aos regimes a que se sujeitam, estrutural e funcionalmente, as empresas estatais ${ }^{1}$.

Neste desígnio, buscando definir uma tipologia ideal de tais empresas, enfrento problemas específicos, relacionados fundamentalmente à determinação dos conceitos de atividade econômica e de serviço público.

Esses problemas suscitam o desenvolvimento de algumas reflexões, atinentes a temas tais como o dos conceitos jurídicos e aquele que tenho referido como o da doutrina real da direito.

Não me conduzem ainda, por certo, tais reflexões, a um entendi. mento bem definido a respeito desses temas. Não obstante, há indicações que tenho alinhadas, na trilha da pesquisa desenvolvida, que me parece adequado aqui postular, menos como teses a sustentar do que como exercício de provocação do debate.

É desde esta última perspectiva, pois, que passo à exposição sintética de parte de tais indicações.

\section{Uso e ocupação com as palavras e expressões jurídicas: ambiguiidade e imprecisão delas}

02. - Os juristas, correntemente, usam determinadas palavras e expressões jurídicas para trabalhar em suas respectivas disciplinas, supondo ser conhecido e assente o sentido que nelas discernem.

1. Uma introdução ao tema pode ser encontrada em meu Elementos de Direito Econ6mico, Editora Revista dos Tribunais, São Paulo, 1981, pags.87/97. Posteriormente, dele tratei, parcialmente, em Disciplina Juridica da Iniciativa Económica, in Caderno de Direito Economico no 1, Editora Resenha Tributaria, 198s, pags. 42 e ss. Deste último texto há trechos de que no presente ensalo lanço mão. 
Isso, contudo, como veremos a seguir, não acorre. Por isso me parece imprescindivel, para que possamos seguir adiante, de modo produtivo, no conhecimento do Direito, ocuparmo-nos com as palavras e expressões jurídicas antes de as usarmos. Essa necessidade, logo demonstrarei ser inafastável.

Ocorre-me, neste passo - e para tanto valho-me da exposição de TÉRCIO SAMPAIO FERRAZ Jr. ${ }^{2}$ - lembrar que a relação básica entre Direito e linguagem pode ser encarada em três diversos sentidos:

a) no primeiro deles considera-se que o Direito tem uma linguagem, tomado o vocábulo como significativo, concomitantemente, de lingua e discurso;

b) no segundo assume-se a existência de um Direito de linguagem, no qual esta aparece como objeto de disciplinação jusnormativa - e não lógica ou gramatical;

c) no terceiro sentido cogita-se do Direito enquanto linguagem, o que leva à afirmação da tese da intranscendentalidade da linguagem.

Fato incontestável é o de que o Direito é, fundamentalmente, comunicação, seja para ordenar situações de conflito, seja para intrumentalizar políticas. Daí a necessidade, inafastável, de penetrarmos o nível lingüístico, na prática das atividades próprias do profissional do Direito. Note-se que, aqui - como adverte TÉRCIO SAMPAIO FERRAZ Jr. ${ }^{3}$ - "o estudo que se desenvolve não é de lingüística, mas jurídico, pois não dispensamos, ao investigar a norma, as características operacionais da teorização jurídica"

03. - Reportando-me, neste passo, às Notas sobre Derecho y Lenguage, de GENARO CARRIÓ ${ }^{4}$, lembro que a linguagem jurídica é nutrida pela linguagem natural, que apresenta uma textura aberta. Por isso mesmo a linguagem jurídica apresenta zonas de penumbra e é, atual ou potencialmente, ambígua e imprecisa.

Assim, ambigüidade e imprecìsão são marcas características da linguagem jurídica. Manifesta-se a primeira em virtude de as mesmas palavras, em diversos contextos, designarem distintos objetos, fatos ou propriedades. Quanto à imprecisão, decorre da fluidez de certas palavras, cujo limite de aplicação é impreciso. Buscando exemplos na linguagem comum, aí teremos os vocábulos jovem, alto, calvo. Transcrevendo CARRIÓ ${ }^{5}$ : "há casos centrais e típicos, frente aos quais ninguém vacilaria em aplicar a palavra, e casos claros de exclusão, em relação os quais ninguém duvidaria em não usá-la. Mas no meio

\footnotetext{
2. Teoria da Norma Jurídica, Forense, Rio de Janeiro, 1978, pág. 6.

3. Ob. cit., pág. 8 .

4. Segunda edición, Abeledo-Perrot, Buenos Aires, 1979.

5. Ob. cit., págs. 31/32.
} 
há uma zona mais ou menos ampla de casos possiveis frente aos quais, quando se apresentam, não sabemos o que fazer".

Cumpre enfatizar, de toda sorte, não ser esse um mal injustificável, de que padece a linguagem jurídica, visto que, se as leis devem ser abstratas e gerais, necessariamente hão de ser expressas em uma linguagem de textura aberta ${ }^{6}$. A consideração do até então exposto, porém, nos remete a uma referência aos conceitos jurídicos.

\section{Conceitos jurídicos indeterminados}

04. - Os fenômenos da ambigüidade e imprecisão das palavras e expressões jurídicas levam ao surgimento dos conceitos juridicos indeterminados.

Excuso-me, neste passo, por não me estender em referências mais detidas à doutrina a esse respeito, relembrando as contribuições de LARENZ, ENGISCH, PHILIPP HECK, QUEIRÓ, ASCARELLI e FORSTHOFF. Isso porém findaria por nos levar a uma ampliação do presente texto, que pretendo seja conciso. E, por tais sendas, não poderiamos deixar de abordar o complexo problema dos "standards" jurídicos e das diretivas do direito francês.

Podemos todavia, sumariamente, afirmar que são indeterminados os conceitos cujos termos são ambíguos ou imprecisos - especialmente imprecisos - razão pela qual necessitam ser completados por quem os aplique. Neste sentido, talvez mais adequadamente pudesse referí-los como conceitos carentes de preenchimento com dados extraídos da realidade. Daí a afirmação, que introduzo, de que os parâmetros para tal preenchimento - quando se trate de conceito aberto por imprecisão $^{7}$ - devem ser buscados na realidade, na consideração das concepções políticas predominantes, concepções essas que variam conforme a atuação das forças sociais ${ }^{8}$.

A verificação de que, tratando-se de conceitos indeterminados, impõe-se o seu preenchimento, reclama a análise de duas questões: quem deve, na instância derradeira, preenchê-los? Como preenchê-los?

\section{O sujeito do preenchimento dos conceitos jurídicos}

05. - Quando temos sob exame um conceito indeterminado, que o legislador não definiu estipulativamente, deverá fazê-lo o aplicador.

6. Neste sentido, ANTONIO ANSELMO MARTINO, Definiciones Legales, in Lenguage y Definicion Juridica, de Warat e Martino, Cooperadora de Derecho y Ciencias Sociales, Buenos Aires, 1973, pág. 65.

7. Quanto aos conceitos abertos por ambigüidade, o seu preenchimento é procedido mediante a consideração do contexto em que inseridos.

8. Neste sentido, FORSTHOFF, Lehrbuch des Verwaltungsrechts, vol. I, C.H., Beck'sche Verlagsbuchhandlung, Munique, $10^{9}$ ed., 1973, págs. 17/18. 
Deixando à parte as relações entre agentes privados e centralizando nossa atenção naquelas em que atua o Estado, poderemos mencionar como aplicadores - sem considerações maiores — a Administração e o Poder Judiciário.

Cuidemos assim, primordialmente, da situação da Administração como sujeito de preenchimento do conceito.

Dir-se-ia, neste passo, que o exercício desta tarefa, pela Administração, supõe exercício de poder político, expresso em termos de discricionariedade.

Dir-se-ia, mais, que a discricionariedade é inafast'́̇vel, visto que, se as leis devem ser abstratas e gerais, necessariamente devem ser expressas em linguagem de textura aberta ${ }^{9}$. Isso contudo, como salienta ANTONIO ANSELMO MARTINO ${ }^{10}$, é antifuncional e introduz. a incerteza entre os destinatários da norma, além de permitir ao "mandamás de turno" que preencha o conceito com a carga emotiva, para a comunidade, de que tal preenchimento é "legal".

06. - Tem-se hoje por superada, no entanto - ao menos no campo doutrinário - a tese que sustenta operar-se no campo da discricionariedade da Administração o preenchimento dos conceitos jurídicos indeterminados. Temos agora entendido - a partir de rica contribuição da doutrina alemã, no tratamento do tema - distinguirem-se fundamentalmente as técnicas da discricionariedade e da utilização dos conceitos indeterminados. A exposição de EDUARDO GARCIA DE ENTERRIA e TOMAS-RAMON FERNANDEZ ${ }^{11}$ a esse respeito é primorosa e dela me valerei, na sintética reprodução de seus argumentos.

Os conceitos indeterminados - que compreendem conceitos de experiência ou de valor - não conduzem a uma situação de indeterminação de aplicação deles. Estas, segundo aqueles autores, só permitem uma "unidade de solução" em cada caso ${ }^{12}$. Assim, quando se fala em boa fé, v.g., o conceito se dá ou não se dá. Em outros termos, em presença de um caso determinado há ou não há boa fé: tertium non datur.

Em razão disso, a aplicação dos conceitos indeterminados só permite uma única solução justa. Contrariamente, o exercício da potestade discricionária permite uma pluralidade de soluções justas ou, em outros

9. A referência à abstração das leis, que volto a fazer, deve ser tomada em termos restritos, sujeita a uma ampla revisão. Pois é certo que uma lei abstrata estará condenada à ineficácia, juridica e social. O destino e vocação delas é a concregăo dos preceitos que encerram. Logo, aqui encontramos situação exemplar de imperiosidade de nos ocuparmos com a expressão em questão: lei abstrata.

10. Ob. cit., pág. 66 .

11. Curso de Derecho Administrativo, Editorial Civitas, Madrid, 1981, vol. I, págs. 385 e sg.

12. Ob. cit., pág. 385 . 
termos, optar entre alternativas que são igualmente justas desde a perspectiva do Direito ${ }^{13}$. Daí porque a discricionariedade é essencialmente uma liberdade de eleição entre alternativas igualmente justas ou entre indiferentes jurídicos, ao passo que a aplicação de conceitos indeterminados é um caso de aplicação da lei.

A conseqüência mais relevante que se extrai dessa distinção respeita ao papel a ser desempenhado pelo Poder Judiciário diante de ambas as hipóteses. Se não lhe cabe, por um lado, a apreciação da decisão discricionária, por outro lhe cumpre, inquestionavelmente, manifestar-se sobre a aplicação, pela Administração, dos conceitos indeterminados.

A distinção entre as duas técnicas - da discricionariedade e dos conceitos indeterminados - permite-nos, assim, a depuração, no campo da primeira delas, de uma série de expressões (da Administração) que notoriamente, em termos de fidelidade aos valores do chamado Estado de Direito, nele não poderiam caber, ainda que lá se as tivesse como incluídas. Por isso que GARCIA DE ENTERRIA e FERNAN$\mathrm{DEZ}^{14}$ - referindo que conceitos como urgência, ordem pública, justo preço, calamidade pública, medidas adequadas ou proporcionais, inclusive necessidade pública, utilidade pública e até interesse público não permitem, em sua aplicação, uma pluralidade de soluções justas, mas apenas uma solução em cada caso - anotam a virtual conversão, para a doutrina germânica, da generalidade das potestades discricionárias em regradas, posto que, explícita ou implicitamente, todas as potestades discricionárias se outorgam para alcançar um interesse público, conceito indeterminado cuja aplicação só permitiria, em cada caso, uma solução justa.

07. - A tese assim sucintamente exposta leva à satisfação de uma necessidade social, qual seja a da ampliação dos controles do Poder Judiciário sobre os atos da Administração. É preciso não esquecer que, como com precisão e incisividade lembra AUGUSTIN GORDILLO "15, "a grande questão do direito administrativo contemporâneo é como controlar uma administração pública que, por seu natural crescimento, tem incrementado consideravelmente, de fato, as rossibilidades de abuso e excesso".

Permito-me, de toda sorte, embora convicto da correção das conclusões a que encaminha a tese postulada, uma ressalva a um dos seus fundamentos, precisamente o que faz repousar na "unidade de solução justa" a distinção entre as duas técnicas consideradas. E isso porque tenho para mim - como enfatizarei a seguir - que, compor-

13. GARCIA DE ENTERRIA E FERNANDEZ, ob. cit., pág. 386.

14. Ob. cit., pág. 387.

15. Problemas de Control de la Administracion Publica en América-Latina, Editoriel Civitas, Madrid, 1981, pág. 12. 
tando o fenômeno jurídico, sempre, mais de uma solução normativa ${ }^{16}$, forçoso é desprezarmos a pretenção da conquista de soluções exatas para eles. No exercício do ofício jurídico - disso estou convicto o que se deve perquirir são soluções corretas, visto que inexistem reais "unidades de soluções justas" ${ }^{17}$.

Penso, assim, podermos apartar as duas técnicas na consideração das matérias que lhes respeitam. No exercício da discricionariedade o sujeito cuida da emissão de juízos de oportunidade, na eleição entre indiferentes jurídicos; na aplicação de conceitos indeterminados, o sujeito cuida da emissão de juízos de legalidade. Por isso é que - e não porque o número de "soluções justas" varia de uma outra hipótese - são distintas as duas técnicas e se buscando, na segunda delas (a da aplicação dos conceitos indeterminados), a formulação de um juízo de legalidade (ou seja: de aplicação da lei), forçoso é entendermos o Poder Judiciário como o sujeito último do preenchimento do conceito, no que se coloca sob o seu controle o exercício anterior dessa mesma atividade pela Admínistração.

Devo passar prontamente, no entanto, à segunda questão formulada.

\section{O preenchimento dos conceitos jurídicos}

08. - Diante da questão - como preencher os conceitos jurídicos abertos? - há, fundamentalmente, dois caminhos a seguir. Incumbirá ao aplicador, ao advogado, ao jurista, para tal efeito, buscar uma definição aristotélica ou, alternativamente, a significação do conceito. Exploremos estas duas sendas, mesmo porque, no palmilhá-las, encontraremos a direção que nos levará a diversa reflexão que pretendo ver debatida.

09. - Neste passo, porém, permito-me a liberdade de, parentética e brevemente, tratar de matéria que talvez mais adequadamente coubesse em nota de rodapé Como, no entanto, não será este texto senão um pretexto para o alinhamento de reflexões que de uma ou de outra forma se interpenetram, interrompo o fio de minha exposição, à qual retornarei.

$\mathrm{O}$ aue pretendo salientar é a circunstância de que não nos basta, enquanto estudiosos do Direito, a prática tão-só da dogmática jurídica, ao gosto e proveito dos glosadores. Inúmeras razões conspiram para tanto.

De uma parte, as normas jurídicas deixam de ter em vista tão somente a harmonização de conflitos de interesses entre partes, identi-

16. FABIO KONDER COMPARATO, Novos Ensaios e Pareceres de Direito Empresarial, Forense, Rio de Janeiro, 1981, pág. IX.

17. Anote-se que GARCTA DE ENTERRIA E FERNANDEZ (ob. cit., pág. 388) aludem à dificuldade de se alcançar a concreção das únicas soluções justas contidas nos conceitos indeterminados. 
ficadas, em determinada relação. Mas, a par dessa função, cumprem também o papel de instrumento de conformação de comportamentos. Vale dizer: a finalidade das normas jurídicas deixa de ser, unicamente, a de ordenação ${ }^{18}$, passando a terem como objetivo a realização de determinadas poíticas. O Direito, então, deixa de ser mero instrumento de conservação da sociedade; volta-se a sua transformação. Daí, aliás, o surgimento das normas objetivo, que tantas vezes tenho mencionado ${ }^{19}$.

De outra, cumpre observar que a tradicionalmente chamada Ciência do Direito não é apenas interpretativa, mas também se é que se a pode, assim, admitir como ciência ${ }^{20}$ - normativa. Por isso que a finalidade dela não é apenas o desejo de saber ou conhecer ${ }^{21}$, mas, sobretudo, a de viabilizar a realização das finalidades da norma jurídica: ordenação e/ou realização de políticas.

Neste ponto, ainda parenteticamente, cabe nova digressão, referida ao âmbito da atuação do jurista. Modernamente, são múltiplas as finalidades da norma jurídica - e não apenas os seus conteúdos, diversos em razão de estarem referidos a diversidade de interesses. Assim sendo, deve necessariamente o jurista tomar também como objeto da chamada Ciência do Direito o conhecimento (a consideração e análise, portanto) de tais finalidades. Isso significa que, no primeiro momento de sua atuação, enquanto jurista - o momento interpretativo - deve ser postulado o conhecimento da finalidade da norma juridica, que não é mais, sempre e necessariamente, a da ordenação. É evidente que, se variam as finalidades das normas jurídicas, deve o jurista preliminarmente determiná-la, em cada caso, para somente após enfrentar o momento normativo da Ciência do Direito. A perquirição de tais finalidades, pois, consubstancia o exercício de atividade própria do jurista - jurídica, pois - integrada no escopo da Ciência do Direito, e não de atividade metajurídica, como costumam afiançar os entusiastas do formalismo jurídico.

Voltemos, de toda sorte, à consideração das alternativas anteriormente referidas.

18. Vide a antológica conferência de PHILIPP HECK, Das Problem der Rechtsgewinnung (em tradução espanhola, de Manuel Enteriza, El Problema de la Creacion del Derecho, Ediciones Ariel, Barcelona, 1961, especialmente págs. 76/77).

19. Vide meu Planejamento Económico e Regra Jurídica, Editoria Revista dos Tribunais, São Paulo, 1978, págs. 242 e ss. e, posteriormente, meu $A$ Lei do Plano, in RDP, vol. 53/54, bem assim meu verbete Norma-objetivo, na Enciclopépia Saraiva do Direito, vol. 54 .

20. Téreio SAMPAIO FERRAZ JUNIOR, A Ciencia do Direito, Editora Atlas, São Paulo, 2: edição, 1980, pág. 15.

21. PHILLIP HECK, ob. cit., pág. 35 e TERCIO SAMPAiO FERRAZ, ob. cit., pág. 15. 


\section{Concepção de definição aristotélica}

10. - As definições aristotélicas são essencialistas. Quem define, segundo este método, busca a determinação da essência do definido. Daí dizer-se que, em sentido estrito, o conceito é a "simplex aprehensio essentiae rei". A tarefa definitória, pois, para ARISTóTELES, consiste na determinação do conteúdo do conceito, mediante a decomposição dos seus elementos constitutivos, o que, na expressão mais singela, supõe a indicação do gênero próximo e da diferença específica.

As críticas maiores que se opõem ao método definitório aristotélico são as seguintes ${ }^{22}$ :

a) supõe a existência de apenas uma definição verdadeira;

b) está vinculado a uma concepção ontológica unidimensional;

c) a pirâmide conceitual termina, no topo, em uma representação vazia de qualquer significação específica.

11. - A suposição da existência de apenas uma definição verdadeira - exata - é insatisfatória para o jurista. Não há, no Direito, definição exata, mas um elenco de definições corretas. Vale dizer: no Direito, para cada problema, podem ser encontradas inúmeras soluções, nenhuma delas exata, mas todas corretas. Pretendo, nisso, afirmar que a complexidade e o dinamismo da realidade social reclamam a disponibilidade de um arsenal de definições corretas para aplicação pelo jurista.

De outra parte, em razão das mesmas causas acima referidas complexidade e dinamismo da realidade social - a prisão do jurista a uma concepção ontológica unidimensional torna-se também insatisfatória.

Por derradeiro, o método aristotélico de definir leva à estruturação de uma pirâmide conceitual, armada sobre uma sucessão de classificações. Cada divisão - observa CASSIRER ${ }^{23}$ - supõe um princípio de classificação que não está contido no classificável, sendo externo a este universo. Como a definição é o "pendant" da divisão, o gênero próximo não pode despreender de si mesmo a diferença específica. Assim, cada novo passo que se dê no caminho da divisão exige a aplicação de conceitos novos, que estão além do cientificamente dado ${ }^{24}$. De outra parte - afirma ainda CASSIRER ${ }^{25}$ - a pirâmide

22. Vide ANTONIO ANSELmo MARTINo, ob. cit., págs. 69/i0 e FRITZ SCHREIER, Conceptos y Formas Fundamentales del Derecho, trad. de Eduardo Garcia de Maynez, Editora Nacional, México, 1975, págs. 26/27.

23. Apud FRITZ SCHREIER, ob. cit., 26/27.

24. Cf. CASSIRER, idem, pág. 27.

25. Idem, ibidem. 
conceitual termina, no topo, na representação abstrata do ser (algo), representação que, por abarcar tudo quanto existe, pode ter qualquer conteúdo e se torna, por fim, vazia de qualquer significação específica. Ora, se a meta que se busca - o topo da pirâmide conceitual - se perde no vazio, todo o procedimento definitório resta comprometido.

As observações neste passo dispostas, a par de colocarem sob suspeição o método aristotélico de definir, ensejam o alinhamento de distinto passo, referido à compostura do conhecimento científico.

\section{Conhecimento científico: axiomatização e conceituação}

12. - Segundo afirma SCHREIER, ${ }^{26}$ valendo de texto de HUSSERL, o fim supremo de todo conhecimento científico é a axiomatização, que permite que todos os procedimentos mentais mediatos sejam reduzidos a simples subsunções do axioma estabelecido sistemática e definitivamente para cada disciplina - a não ser que se trate da lógica formal pura e se pretenda reforçar a subsunção relativamente aos axiomas desta última.

Daí ser despiciendo qualquer esforço no sentido de definição do objeto de qualquer ciência: o que importa é a formulação de axiomas, dos quais se possa inferir a totalidade de conhecimentos de cada território científico ${ }^{27}$. Por isso é inteiramente irrelevante para a Geometria definir espaço, para a Aritmética definir número. O que nessas ciências se coloca é tão-somente a exposição de uma série de princípios supremos.

A ciência, assim, é um sistema fechado, com legalidade própria, que não se abre para o campo da metaciência precisamente porque seus conceitos fundamentais não são definidos. Em lugar de conceitos fundamentais - cuja definição, pelo método aristotélico, supõe o recurso a outros conceitos, externos ao sistema - a ciência postula axiomas.

Desta sorte, se pretendermos referir uma ciência do Direito há de ser ela concebida como um sistema fechado - atemporal e inespacial - no qual não há lugar para a conceituação do Direito. Seu objeto, à moda de KELSEN, é o conhecimento, tão-só, da estrutura formal do Direito, no exame restrito, porém, da norma jurídica.

26. Ob. cit., págs. $27 / 28$.

27. Cf. FRITZ SCHREIER, ob. cit., pág. 28. Observe-se, porém, que a tentação do conhecimento total deve ser recusada. Como observa HERMANN BONDI (A Tentação do Conhecimento Total, in Enciclopédia da Ignorância, Duncan \& Weston Smith-org. tradução. Editora Universidade de Brasília, 1981), "na verdade, pode-se dizer que a ciência só é possivel porque se pode afirmar algo sem saber-se tudo. Portanto, trabalhar no sentido da obtenção do conhecimento total pode ser um equívoco essencial. muito mais produtivo extrair o máximo do que se sabe e acrescentar novos elementos a esse núcleo quando for possivel". 


\section{Ciência do Direito (teoria jurídica formal)}

\section{e doutrina real do Direito}

13. - A ponderação das observações anteriormente alinhadas tem para mim o valor de explicar a postura dos adeptos da teoria pura do Direito. Afastando-me, neste passo, das considerações de FRITZ SCHREIER - da qual me vali largamente, até este momento de minha exposição - tenho que a virtude do pensamento kelseniano está justamente na eleição de axioma que, por não ser definivel, confere ao Direito a compostura de ciência. Pretendo se alinhe, a partir deste ponto, outra série de reflexões que ofereço a debate.

14. - A postura dos adeptos da teoria pura do Direito nos conduz, em determinados momentos, a verdadeiros "culs de sac". Isso se verifica, ordinariamente, quando, no auge de uma discussão, emitem a tradicional sentença: "isso é metajurídico". É necessário observar, contudo, que sob essa afirmação repousa a velha questão da oposição entre Ciência e Filosofia. Diante das duas indagações - "quid juris, quid jus" - o formalista do Direito só tem resposta para a primeira. A atenção que fosse conferida à segunda faria desmoronar todo o edifício da Ciência do Direito.

15. - Tenho me preocupado, em escritos anteriores, em demonstrar a insuficiência da postura formalista. Veja-se, a respeito, meu Elementos de Direito Econômico ${ }^{28}$, especialmente págs. 3/7. Em oportunidade mais recente ${ }^{29}$, acuso os adeptos da teoria pura do Direito da adoção de uma postura ideológica liberal, que não é coerente com a noção de Estado Social do Direito ${ }^{30}$. Além disso, imputo a eles a adoção de uma postura metodológica também equívoca, postura essa peculiarizada pela busca da lógica das noções jurídicas exclusivamente na razão teórica. Esse - afirmei então - o seu grande equívoco, pois é evidente que as noções jurídicas não devem ser apreciadas somente desde o ponto de vista teórico, dado que é como produto de

28. Ob. cit. Nesse texto reprodizo, sumariamente, exposição de BOBBIO a respeito da inocuidade da concepção, de Kelsen, da norma fundamental. BOBBIO chega a referí-la como sispérflua. Não obstante, para mim de mado surpreendente, o próprio BOBBIO, em conferência que pronunciou, em 13 de setembro de 1982, na Faculdade de Direito da Universidade de São Paulo, sobre o tema Direito e Poder, adotou como premissa fundamental dessa outra exposição precisamente a concepção de norma fundamental, que anteriormente qualificara de supérflua.

29. Parecer inédito, sobre poder regulamentar.

30. Afirmei, então, entre outros pontos, que os adeptos da doutrina liberal kelseniana são incapazes de perceber a realidade de Estado de nossos dias, visualizando-o exclusivamente como aquele que se relaciona aos particulares na situação de titular de "jus imperii", na qual estes se colocam em relação de subordinação ou dependência àquele. São herdeiros da concepção de Estado que nasceu à sombra da revolução burguesa e que levou, no campo econômico, às garantias formais da liberdade de concorrência e da propriedade privađa e, no campo político, à organização do poder, segundo o principio da sua separação. Daí a sua adesão radical às teorizações do positivismo jurídico. 
situações histórico-políticas (e não da razão teórica) que elas adquirem sua lógica própria ${ }^{31}$.

Todos esses pontos críticos, no entanto, são produto de necessidade interna da teoria pura do Direito. O rompimento dos limites do seu universo, constituído pela matéria do abstrato, para o encontro com o mundo do real, importaria a ruptura do sistema e o perecimento da Ciência do Direito.

16. - A sujeição a tais limitações parece-me perniciosa e impõe a introdução da distinção entre a Ciência do Direito e a doutrina real do Direito.

A prática da dontrina real do Direito supõe o tratamento do Direito como fenômeno social - portanto indissociável da realidade - e não como expressão de uma estrutura formal. Devo observar não divisar nenhuma diminuição intelectual nesta opção. Se o exercício da ciência jurídica impõe a prisão do jurista ao âmbito estrito da teoria jurídica formal, abstenhamo-nos de fazer ciência. Pois, como demonstrarei a seguir, o preenchimento dos conceitos jurídicos indeterminados é impraticável dentro dos limites fechados dessa Ciência do Direito.

17. - Com efeito, a busca daquele preenchimento, como assinala CARRIó ${ }^{32}$, é praticada pelos adeptos da teoria pura do Direito mediante a oficialização de uma apenas das significações possíveis do conceito, com o abandono das restantes - isto é, mediante a consumação de uma redefinição estipulativa. Com isso - prossegue CARRIó constrói-se, em nome da chamada pureza metódica, um aparato conceitual coerente e "econômico", a partir de um grupo restrito de noções básicas.

Exemplo marcante disso encontra-se no conceito de serviço público desenvolvido pelos formalistas, que não apenas é insuficiente, mas também terrivelmente enganoso, na medida em que coloca em risco a operacionalidade de preceitos constitucionais, tais como o do $\S 1^{\text {o }}$ do artigo 170 da vigente Constituição Federal. Não obstante, em sua formulação, a pureza metódica do sistema jurídico é inteiramente resguardada.

Vê-se para logo que tal expediente é insatisfatório, cumprindo ao jurista romper aqueles limites, caminhando do universo, restrito, da Ciência do Direito para o campo de horizontes inatingíveis ${ }^{33}$ - por isso mesmo extremamente mais rico e desafiador - da doutrina real do Direito.

31. Neste sentido, FORSTHOFF, ob. cit., págs. 132/133.

32. Nota preliminar a W.N. Hohfeld, Conceptos Jurídicos Fundamentales, trad. de Genaro Carri6, Centro Editor de América-Latina, Buenos Aires, 1968, págs. 10/11.

33. Vide, na nota 27, referência à tentação do conhecimento total. 


\section{Os conceitos jurídicos: sua operacionalidade ou funcionalidade}

18. - Os conceitos jurídicos, como adverte ALF ROSS ${ }^{34}$, não são idéias, reflexões sobre a essência das coisas, mas ferramentas que forjamos para descrever a realidade. Daí porque há perguntas de formulação incabível no nível do jurídico.

Podemos perguntar - continua ALF ROSS - "o que é água?", visto que não resta dúvida quanto ao significado da palavra "água". A tal pergunta respondemos com um enunciado revelador da essência da água. Se, no entanto, há dúvida quanto ao significado de uma palavra, a pergunta "o que é" torna-se despropositada. Não se trata de encontrarmos dificuldades para respondê-la; o problema está na própria pergunta, que não poderia ter sido formulada.

Em verdade, ao jurista não importa descobrir a essência das coisas, mas sim descobrir o significado dos conceitos jurídicos. Cabe-lhe, assim, inicialmente enunciar o contexto em que se insere o conceito e, posteriormente, buscar uma definição operacional (funcional) - e não essencialista - dele.

Neste ponto, retornando à distinção entre a Ciência do Direito e a doutrina real do Direito, podemos dizer que a primeira - teoria jurídica formal - é um sistema lógico e a segunda é, também, sistema semiológico.

19. - Insisto em que é irrelevante para o jurista a determinação da essência dos objetos, o que supõe a sua naturalidade. Pois é certo que há expressões jurídicas - conceitos - a que não corresponde nenhum objeto, não sendo possível tratar-se, portanto, da naturalidade delas.

Retornando, neste passo, à exposição de SCHREIER ${ }^{35}$, veremos que o ato de expressão compreende quatro elementos: a) o aspecto físico da expressão; b) a significação; c) o objeto; d) a intuição sensível.

Por conceito pode-se entender tanto a significação quanto o objeto.

Pois os conceitos jurídicos são referidos à significação e não a objetos, que possam ser identificados em sua essência. Passa-se, com eles, o que ocorre com o número, que não tem objeto. Não há qualquer sentido, por exemplo, em pesquisarmos a naturalidade da hipoteca ${ }^{36}$, visto que hipoteca é palavra que não tem objeto.

É certo que há expressões jurídicas que tem objeto, mas o que continua a importar, para o jurista, sempre, é a sua significação.

34. El Concepto de Validez y Otros Ensayos, trad. de Genaro Carri6 y Osvaldo Paschero, Centro Editor de América Latina, Buenos Aires, págs. 85/86.

35. Ob. cit., pags. $35 / 36$.

36. O exemplo é de ANTONIO ANSELMO BARTINO, ob. cit., pág. 71. 
$\mathrm{E}$ isso ocorre justamente porque os conceitos jurídicos são usados não para definir essências, mas sim para permitir a viabilizar a aplicação de normas jurídicas. Esse, o seu destino e a sua vocação ${ }^{37}$.

20. - Visto isso e reiterado o fato de que a doutrina real do Direito é também um sistema semiológico, teremos que o preenchimento dos conceitos jurídicos indeterminados deve ser procedido, inicialmente, desde a consideração dos fins para os quais serão usados. Aí, definidamente, a marca da operacionalidade/funcionalidade deles.

Apurada a finalidade de utilização do conceito - o que supõe a consideração do contexto em que será inserido - impõe-se assumirmos que, sendo imprecisa a expressão, o sujeito emissor da norma reportou-se ao sentido que ela assume na linguagem natural. Explicita CELSO ANTONIO BANDEIRA DE MELLO ${ }^{38}$ : “... ao sentido comum da expressão, isto é, ao prevalente ao lume dos padrões de cultura de uma época, das convicções predominantes da sociedade".

21. - Cumpre-nos assim, enquanto cultores da doutrina real do Direito, porque envolvidos com a realidade social cuidando da aplicação e da operacionalidade (eficácia) das normas jurídicas, buscar o preenchimento dos conceitos indeterminados mediante o aproveitamento dos subsídios da realidade social, nos quadrantes dos fins em razão dos quais a clarificação do conceito é pretendida.

Lembro que o grau de complexidade desta tarefa será menor na medida em que contemplada, no contexto normativo a considerar, uma norma-objetivo ${ }^{39}$, na qual deverão ser buscadas pautas para aquele preenchimento.

\section{Ainda a doutrina real do Direito}

22. - No mais, devo ressaltar que não pretendo, neste texto, sumariamente repudiar a postura dos adeptos da teoria pura do Direito. Pelo contrário, explicando-a como manifestação - deles - de apego à pureza metódica, procuro apenas pontualizar o fato de que a teoria formal está colocada em nível diverso de indagação (enquanto sistema lógico) daquele ocupado pela doutrina real do Direito (enquanto sistema semiológico). Não se trata de valorar a teoria pura do Direito entre os extremos do falso e do verdadeiro, mas de apontar a verificação de que a tenho por insatisfatória e meramente parcial. A compreensão plena do Direito - não apenas o "quid juris", mas também o "quid jus" - reclama o exercício das práticas da doutrina real do Direito,

37. A propósito, afirma CELSO ANTONIO BANDEIRA DE MELLO (Prestação de Serviço Público e Administração Indireta, Editora Revista dos Tribunais, São Paulo, 1973, pág. 18) que "um conceito jurídico é necessariamente um ponto terminal de regras, um termo relacionador de principios e regras"

38. Ob. cit., págs. $22 / 23$.

39. Sobre a noção norma-objetivo, vide nota 19. 
ainda que ao custo, menor, de não estarmos alinhados entre os olimpicamente perfilados cultores da "soi disant" única e definitiva Ciência do Direito.

23. - É necessário que se afirme, ainda, que o Direito não é só norma mas ordenamento, norma e decisão. O anseio e $a$ aspiração de KELSEN, em erigir uma Ciência do Direito, leva-o - e aos adeptos da teoria pura do Direito - à constituição apenas de uma ciência da norma jurídica, parcial e fracionada, em presença do Direito, a partir do axioma da norma fundamental.

É imperioso verificarmos que o Direito é pluridimensional, dotado de conteúdo empírico e axiológico, e constitui verdadeira prudência - e não ciência. Produto cultural - na medida em que é uma invenção do homem - urdido a partir do confronto que se estabelece entre as forças sociais, e também expressão ideológica, há que tomá-lo o jurista como objeto de indagação desde a perspectiva teleológica. $O$ desafio que permanece, ao final desta breve enunciação de reflexões menores, é o atinente à necessidade, com precisão maior, sublinharmos o perfil da doutrina real do Direito - o que nos levará, por certo, de encontro a uma série sempre maior de inquietações e perplexidades. 